\title{
SOBREVIVÊNCIA E CRESCIMENTO INICIAL DE PLÂNTULAS DE Euterpe edulis MART. TRANSPLANTADAS PARA CLAREIRAS E SUB-BOSQUE EM UMA FLORESTA ESTACIONAL SEMIDECIDUAL, EM VIÇOSA, MG ${ }^{1}$
}

Tiago Maciel Ribeiro², Sebastião Venâncio Martins³ ${ }^{3}$ Vanessa Mendes Lana² e Kelly de Almeida Silva²

RESUMO - Este estudo teve como objetivos avaliar a sobrevivência e crescimento inicial de plântulas de Euterpe edulis Mart. transplantadas para duas condições de luz: clareira e sub-bosque, além de discutir seu comportamento ecofisiológico. Foram transplantadas 90 plântulas com altura entre 5 e $25 \mathrm{~cm}$ em seis parcelas: três em subbosque e três em clareiras, no espaçamento 2 x $2 \mathrm{~m}$ em três linhas de plantio, com cinco plântulas cada. A porcentagem de sobrevivência (geral) no período do estudo foi de 36,7\%, enquanto nas clareiras foi de 53,3\% e no sub-bosque, 20\%. Uma regressão não linear mostrou relação positiva entre abertura de dossel e sobrevivência de plântulas de E. edulis. A maior taxa de sobrevivência das plântulas no ambiente de clareira em relação ao sub-bosque pode ser explicada pelo excesso de sombreamento no último, causada pela baixa porcentagem de abertura do dossel (4,78\%). A abertura do dossel não influenciou significativamente no crescimento das plântulas.

Palavras-chave: Regeneração, Restauração florestal, Euterpe edulis e Reserva Mata do Paraíso.

\section{SURVIVAL AND INITIAL GROWTH OF Euterpe edulis MART. SEEDLINGS TRANSPLANTED TO GAPS AND UNDESTORY IN A SEMIDECIDUOUS FOREST, VIÇOSA, MG}

\begin{abstract}
The objective of this study was to evaluate the survival and initial growth of Euterpe edulis seedlings transplanted to two light conditions: gaps (clearing area) and understory. Moreover it discusses their ecophysiologycal behavior on these two micro-sites. Ninety seedlings of Euterpe edulis with height about 5 and $25 \mathrm{~cm}$ were transplanted in six plots: three on understory and three 3 on gaps (clearing area) in a $2 \times 2 \mathrm{~m}$ spacing with three rows of plants containing five plants each one. The survival percentage during the period of the study was $36.7 \%$ whereas on gaps (clearing area) it was $53.3 \%$ and on understory it was $20 \%$. A non-linear regression showed a positive relationship between canopy openness and seedling of $\boldsymbol{E}$. edulis. The higher survival rate of seedlings on gaps (clearing area) than on understory can be explained by the excess of shade on the latter, caused by the low canopy openness percentage (4.78\% on average). There was no influence of canopy openness on seedling height growth.
\end{abstract}

Keywords: Regeneration, Forest restoration, Euterpe edulis and Mata do Paraíso Reserve

\section{INTRODUÇÃO}

No Brasil, várias espécies de palmeiras produzem palmito comestível. Entre elas, a espécie mais conhecida e apreciada é Euterpe edulis Martius, comumente chamada de palmiteiro-juçara, jiçara ou ripeira (LIN, 1988), pertencente à família Arecaceae. Aespécie destaca-se das demais palmeiras pela qualidade e rendimento em palmito. Ocorre desde o Sul da Bahia $\left(15^{\circ} \mathrm{S}\right)$ até o Norte do Rio Grande do Sul ( $\left.30^{\circ} \mathrm{S}\right)$, ao longo do litoral brasileiro, no domínio Floresta Atlântica, em trechos de Floresta Estacional Semidecidual (REIS et al., 2000). Logo, percebe-se que a espécie é amplamente distribuída geograficamente, apresenta grande abundância na área

\footnotetext{
${ }^{1}$ Recebido em 18.06.2010 e aceito para publicação em 31.10.2011.

${ }^{2}$ Programa de Pós-Graduação em Ciencia Florestal pela Universidade Federal de Viçosa, UFV, Brasil. E-mail: <tiagomribeiro84@hotmail.com>. ${ }^{3}$ Laboratório de Restauração Florestal, Departamento de Engenharia Florestal, Universidade Federal de Viçosa, UFV, Brasil. E-mail: <venancio@ufv.br>.
} 
de ocorrência, curto ciclo de vida, posicionamento no estrato médio da floresta, forte interação com a fauna e comercialização garantida (REIS; GUERRA, 1999).

O Brasil é o maior produtor e exportador de palmito em conserva do mundo. Contudo, a exploração, na sua maioria, é oriunda de atividade extrativista das reservas naturais ainda existentes (BOVI, 1993). Euterpe edulis perfilha apenas uma vez e demora sete anos, em média, para atingir o tamanho de corte, sendo o extrativismo atividade predatória da espécie.

Sua introdução em florestas secundárias tende a acelerar a sucessão ecológica, pois, como produz grande quantidade de frutos atrativos à fauna silvestre, possibilita que várias espécies de aves (jacus, jacutingas, arapongas, sabiás, tucanos) e mamíferos (preás, porcos do mato, antas, macacos e até morcegos frugívoros) passem a colonizar e dispersar suas sementes e de muitas outras espécies, inclusive de outras comunidades vegetais relativamente próximas (MARTINS; DE LIMA, 1999). Em contrapartida, sua retirada indiscriminada da vegetação causa severos impactos ambientais negativos sobre a flora e fauna, em razão da sua forte contribuição na dinâmica e estrutura das florestas tropicais onde ocorre. A importância ecológica da $E$. edulis é também reforçada pelo fato de ser uma das poucas espécies comercialmente exploradas que pode ser cultivada em florestas nativas, permitindo a conservação destas por meio de sistemas de enriquecimento e manejo sustentável.

O palmito-juçara é uma espécie que apresenta estratégia de regeneração do tipo banco de plântulas, com distribuição espacial agregada próximo das plantasmatriz (FANTINI et al., 2000). Esse banco de plântulas de alta densidade gera forte competição intraespecífica por nutrientes, luz e água, além de aumentar a vulnerabilidade do banco ao ataque de pragas e doenças. Esse fato leva à baixa sobrevivência das plântulas de E. edulis nas florestas tropicais, a qual se intensifica com a contínua degradação desses ambientes, uma vez que reduz a população adulta produtora de sementes e da sua dependente população da fauna dispersora, que contribui para uma distribuição mais dispersa das sementes e, consequentemente, das plântulas.

Atualmente, a espécie E. edulis é um dos produtos mais explorados na Floresta Atlântica (REIS; GUERRA, 1999), contribuindo para a degradação do meio ambiente e gerando preocupação para a preservação da espécie, uma vez que não há rebrota após o corte para a extração do palmito (MORTARA; VALERIANO, 2001), estando atualmente em acelerado processo de extinção.

Em áreas mais fortemente perturbadas, como é o caso dos fragmentos florestais na região da Zona da Mata de Minas Gerais, é preciso intensificar a reposição da espécie por meio do replantio, já que sua dispersão pela fauna está bastante comprometida. Para aperfeiçoar essa técnica, é necessário o conhecimento do comportamento dessa espécie em diferentes microssítios de luz (clareira e sub-bosque), a fim de maximizar a sobrevivência das plântulas através do transplantio.

Existem poucos estudos que relatam a técnica de resgate de indivíduos regenerantes de espécies tropicais. Esse método é de grande importância não apenas para a constituição da diversidade necessária em projetos de restauração florestal, mas também pela possibilidade de conservação de material genético que, de outra forma, seria suprimido (PAREJA, 1998; VIANI et al., 2006; BRITO; MARTINS, 2007).

Nesse contexto, este trabalho visou aplicar a técnica do resgate e transplante de plântulas de E. edulis em condições naturais da floresta, avaliando a sobrevivência e o crescimento inicial dos indivíduos transplantados em duas condições de luz: clareira e sub-bosque, na Reserva Mata do Paraíso em Viçosa, MG, bem como sua viabilidade em um modelo de manejo ecológico para a espécie visando acelerar a restauração de florestas secundárias, o que beneficiará não só a espécie estudada, como também a fauna dispersora e populações tradicionais que se dedicam ao seu extrativismo.

\section{MATERIAL E MÉTODOS}

\subsection{Caracterização da área de estudo}

O estudo foi conduzido na Reserva Mata do Paraíso (Estação de Pesquisa, Treinamento e Educação Ambiental Mata do Paraíso), pertencente à Universidade Federal de Viçosa (UFV) e distante cerca de 10 km dessa Instituição. A reserva Mata do Paraíso (2048’07"S e 4251’31"W) possui 195 ha de área e altitudes variando de 690 a 800 m, estando localizada no município de Viçosa, Zona da Mata de Minas Gerais (BRAZ et al., 2002).

O clima na região é do tipo Cwb (Köppen), mesotérmico com verões quentes e chuvosos e invernos frios e secos. A temperatura média anual é de $21,8^{\circ} \mathrm{C}$ e 
a precipitação pluviométrica média anual, de 1.314,2 mm. A vegetação da reserva é composta por trechos de Floresta Estacional Semidecidual (VELOSO et al., 1991), compondo um mosaico de diferentes estádios sucessionais e pequenas áreas de brejo (SILVA JÚNIOR et al., 2004). De acordo com o balanço hídrico de Thornthwaite e Matther (GOLFARI, 1975), no município de Viçosa, MG, ocorrem deficiências hídricas de abril a fins de agosto, sendo mais intensas durante os meses mais frios do ano; em setembro, inicia-se a estação das chuvas, ocorrendo excedentes hídricos até fins de março. Portanto, tem-se na região uma marcada estacionalidade climática.

O relevo é do tipo ondulado a fortemente ondulado, com encostas embutidas em vales de fundo chato, formados por terraços, onde meandram cursos d'água pouco expressivos (CORRÊA, 1984; LEAL FILHO, 1992).

Na área da Reserva predominam solos de duas classes: nos topos e nas encostas das elevações, com predominância dos Latossolos Vermelho-Amarelos álicos, enquanto nos terraços predomina o Podzólico VermelhoAmarelo Câmbico fase terraço (REZENDE, 1971; CORRÊA, 1984; BARUQUI et al., 1985).

\subsection{Resgate de plântulas de Euterpe edulis}

Foram transplantadas plântulas de E. edulis com altura entre $5 \mathrm{~cm}$ e $25 \mathrm{~cm}$, que ocorrem de forma agregada em trechos de floresta madura da reserva. As plântulas foram retiradas do solo com o auxílio de uma pá de jardinagem, com cuidado para não danificar seu sistema radicular, e acondicionadas em baldes contendo água. Foram feitos cortes para eliminar metade da área foliar de cada plântula, em todas as suas folhas, o que, além de diminuir a transpiração e aumentar a probabilidade de sobrevivência da plântula resgatada, permite observar a formação de folhas novas em mudas transplantadas com sucesso.

As plântulas retiradas do solo e armazenadas em baldes com água foram imediatamente transplantadas em duas condições de luz: sub-bosque e clareiras, em dia chuvoso. Foram selecionadas três clareiras naturais com classe de tamanho semelhante, variando de 67 a $80 \mathrm{~m}^{2}$, para as quais as plântulas foram transplantadas. O plantio adotado foi em linhas com espaçamento de 2 × 2 m, sendo plantadas três linhas em cada clareira contendo cinco plântulas cada linha. A linha do meio foi demarcada no centro da clareira.

O transplante para o sub-bosque foi realizado no entorno de cada clareira. A partir de uma distância de $3 \mathrm{~m}$ da borda da clareira para o interior da floresta foram plantadas três linhas paralelas, mantendo o espaçamento de 2 x 2 m entre plântulas. Da mesma forma que nas clareiras, cada linha de plantio recebeu cinco plântulas resgatadas, totalizando 45 plântulas para a condição de clareira e 45 para a condição de sub-bosque

Foram realizadas quatro avaliações (aos 6, 8, 12 e 18 meses após o transplantio das plântulas), para averiguar a sobrevivência sob cada condição de luz e acompanhar o crescimento inicial das plântulas sobreviventes. Os dados foram analisados através do Teste t em amostras independentes. Para a avaliação do crescimento das plântulas foi realizada a medição de altura total destas, a partir do nível do solo. Não foi feita nenhuma intervenção nas áreas de transplantio (como adubação, irrigação, coroamento), justamente

Tabela 1 - Densidade do banco de plântulas de Euterpe edulis $\left(\mathrm{n}^{\circ}\right.$. de indivíduos $/ \mathrm{m}^{2}$ ) no início e no final do período de estudo e porcentagem de sobrevivência no período citado. Parcelas seguidas de asterisco indicam a retirada de 30 plântulas em cada banco utilizadas no transplantio.

Table 1 - Euterpe edulis seedling bank density (no. individuals $/ \mathrm{m}^{2}$ ), at the beginning and at the end of the study and survival percentage during this period. Plots followed by asterisk indicate the removal of 30 seedlings in each bank for transplanting.

\begin{tabular}{|c|c|c|c|}
\hline & $\begin{array}{c}\text { Número de indivíduos } / \mathrm{m}^{2} \\
\text { no início: T0 }\end{array}$ & $\begin{array}{l}\text { Número de indivíduos } / \mathrm{m}^{2} \\
\text { no final: } T f\end{array}$ & $\begin{array}{l}\text { Sobrevivência } \\
\text { no período }(\%)\end{array}$ \\
\hline$\overline{\text { Banco } 1 *}$ & 165,5 & 81,5 & 49,25 \\
\hline Banco $2 *$ & 145 & 72 & 49,66 \\
\hline Banco 3 & 63 & 34 & 53,97 \\
\hline Banco 4 & 65 & 27,5 & 42,31 \\
\hline Banco $5 *$ & 148 & 76 & 51,35 \\
\hline Banco 6 & 94,5 & 33 & 34,92 \\
\hline Média & 113,5 & 54 & 46,91 \\
\hline
\end{tabular}


para que se possa observar o comportamento da espécie em ambiente natural, buscando entender melhor suas características ecofisiológicas.

Foram marcadas também, nas áreas de sub-bosque, seis parcelas de $2 \times 1 \mathrm{~m}$ contendo banco agregado de plântulas de E. edulis, nas quais foram contados todos os indivíduos. Após oito meses, foi realizada outra contagem para comparar a sobrevivência nessas parcelas com as mudas transplantadas. Escolheu-se esse intervalo de tempo, a fim de realizar a contagem antes do novo período de dispersão de frutos pelas plantas-matriz, o que levaria ao aumento do número de indivíduos na parcela via germinação, comprometendo a comparação entre os tratamentos. A contagem dos indivíduos sobreviventes nas parcelas de transplantio também foi realizada para efeito de comparação.

No centro de cada clareira e nas parcelas do subbosque foram obtidas fotografias hemisféricas digitais para determinação da porcentagem de abertura do dossel, em cada condição de luz, utilizando-se o software Gap Light Analyser. A porcentagem de abertura do dossel tem relação estreita com a quantidade de energia radiante, que alcança diretamente a superfície da área em questão, ou seja, quanto maior a abertura do dossel, maior a energia luminosa que atinge diretamente a superfície do solo, podendo influenciar o crescimento dos indivíduos que ali se estabelecem, a temperatura e umidade do ar e do solo etc.

\section{RESULTADOS}

A porcentagem de sobrevivência em ambas as condições no período do estudo foi de 36,7\%. Das 90 plântulas transplantadas, 57 não sobreviveram, das quais 21 foram plantadas em clareiras e 36 no sub- bosque sombreado. Em média, a porcentagem de sobrevivência das plântulas transplantadas para clareiras foi de $53 \%$ e para o sub-bosque sombreado, de $20 \%$.

Quando foram confrontados os resultados obtidos através do transplante de plântulas de E. edulis com os observados nas seis parcelas contendo banco de plântulas de alta densidade da espécie (Tabela 1), aos oito meses após o transplantio, observou-se diferença significativa nas porcentagens de sobrevivência (74,4\% e $46,91 \%$, respectivamente, $\mathrm{p}=0,003$ pelo teste t a $5 \%$ de probabilidade).

Considerando o número total de plântulas transplantadas, a média de altura aos oito meses foi de 6,4 cm. Se considerar apenas as plântulas sobreviventes, a média de altura foi de $17,5 \mathrm{~cm}$, e na ocasião do resgate, ou seja, no momento do transplante, a média era de $16,3 \mathrm{~cm}$. Vale ressaltar que, em várias ocasiões, ocorreram morte da folha mais velha e emissão de folha nova na base da plântula, diminuindo sua altura total e, consequentemente, diminuindo também a média geral e da sua parcela; o que ocorreu com maior frequência na parcela denominada sub-bosque 3 , que apresentou por isso taxa de crescimento negativa (Tabela 2). Foi observado crescimento inicial bastante lento das plântulas transplantadas, sendo de $0,05 \mathrm{~cm}$. mês ${ }^{-1}$ e 0,09 cm. mês-1 as taxas médias de crescimento em altura total na clareira e no sub-bosque sombreado, respectivamente, durante o período do estudo. Não foi verificada influência de diferentes condições de luz no crescimento em altura.

Analisando os valores de porcentagem da abertura de dossel, observou-se diferença significativa na abertura média do dossel entre clareiras e sub-bosque $(\mathrm{p}=0,002$, pelo teste t a $5 \%$ de probabilidade) (Tabela 3 ).

Tabela 2 - Média de altura no início e no final do período de estudo, porcentagem de sobrevivência e ritmo de crescimento por clareira e sub-bosque, na última avaliação.

Table 2 - Height average, at the beginning and at the end of the study; survival percentage and growth rhythm per gap and understory, related to the last survey.

\begin{tabular}{|c|c|c|c|c|}
\hline Parcelas & $\begin{array}{c}\text { Média de altura (cm) } \\
\text { no início: H0 }\end{array}$ & $\begin{array}{c}\text { Média de altura }(\mathrm{cm}) \\
\text { no final:Hf }\end{array}$ & $\begin{array}{c}\text { Sobrevivência } \\
\text { (\%) }\end{array}$ & $\begin{array}{c}\text { Taxa Crescimento } \\
\text { (cm/mês) }\end{array}$ \\
\hline Clareira 1 & 19,5 & 20,5 & $40 \%$ & 0,06 \\
\hline Clareira 2 & 15,5 & 16 & $53,3 \%$ & 0,03 \\
\hline Clareira 3 & 15 & 16,5 & $66,7 \%$ & 0,08 \\
\hline Sub-bosque 1 & 18,5 & 21 & $33,3 \%$ & 0,14 \\
\hline Sub-bosque 2 & 15,5 & 19 & $6,7 \%$ & 0,19 \\
\hline Sub-bosque 3 & 14 & 12,5 & $20 \%$ & $-0,08$ \\
\hline Média clareiras & 16,7 & 17,7 & $53,3 \%$ & 0,06 \\
\hline Média sub-bosques & 16 & 17,5 & $20 \%$ & 0,08 \\
\hline Média total & 16,3 & 17,6 & $36,7 \%$ & 0,07 \\
\hline
\end{tabular}

Revista Árvore, Viçosa-MG, v.35, n.6, p.1219-1226, 2011 
Tabela 3 - Porcentagem de abertura do dossel em cada parcela de transplantio.

Table 3 - Canopy openness percentage on each transplant plot.

\begin{tabular}{lcc}
\hline Parcelas & $\begin{array}{c}\text { Abertura do } \\
\text { dossel (\%) }\end{array}$ & $\begin{array}{c}\text { Área da } \\
\left.\text { clareira(m }{ }^{2}\right)\end{array}$ \\
\hline Clareira 1 & $18,56 \%$ & 80 \\
Clareira 2 & $14,19 \%$ & 72 \\
Clareira 3 & $12,93 \%$ & 67 \\
Sub-bosque $\mathbf{1}$ & $9,46 \%$ & \\
Sub-bosque 2 & $3,42 \%$ & \\
Sub-bosque $\mathbf{3}$ & $1,47 \%$ & \\
Média para clareiras & $15,23 \%$ & \\
Média para sub-bosques & $4,78 \%$ & \\
\hline
\end{tabular}

Foi ajustada uma regressão não linear (logarítmica) aos dados da porcentagem de sobrevivência em função da abertura do dossel, que mostrou relação positiva entre abertura do dossel e sobrevivência de plântulas de E. edulis (Figura 1).

\section{DISCUSSÃO}

Os resultados de sobrevivência das plântulas de E. edulis corroboraram estudos de Reis (1987) e Schaefer (1999), que consideraram que o banco de plântulas da espécie foi estimulado a crescer em condições de perturbação do dossel florestal, devido ao aumento dos níveis de luz.

A maior sobrevivência das plântulas no ambiente de clareira em relação ao sub-bosque pode ser explicada pelo excesso de sombreamento no último, causada pela baixa porcentagem de abertura do dossel (4,78\%, em

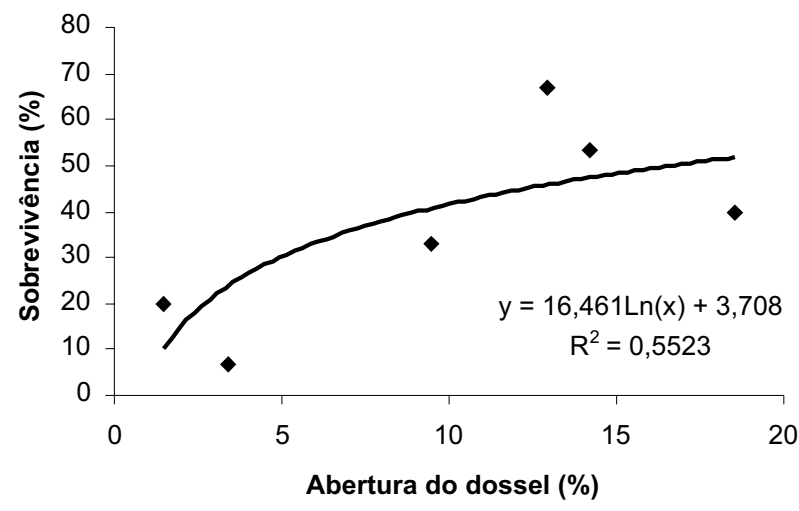

Figura 1 - Relação logarítmica entre abertura do dossel (\%) e sobrevivência (\%), ao final do estudo.

Figure 1 - Logarithmic relation between canopy openness (\%) and survival (\%), at the end of the study. média), ocasionando mortalidade de $80 \%$ das plântulas. Já no ambiente de clareira, cuja porcentagem de abertura do dossel era de 15,23\% em média, a mortalidade foi de $47,7 \%$. O excesso de sombreamento pode não ter disponibilizado energia luminosa suficiente para o desenvolvimento das plântulas, retardando sua atividade fisiológica. Houve tendência de aumento da sobrevivência com o incremento da abertura do dossel, que é uma medida indireta dos níveis de luz que atingem o nível do solo da floresta (Figura 1). Nessa figura, pode-se observar que 55,3\% da variação da porcentagem de sobrevivência é explicada pela abertura do dossel.

Yamazoe et al. (1990) estudaram o enriquecimento de matas secundárias utilizando mudas de E. edulis em três estágios de sucessão (capoeirinha, capoeira e capoeirão). Verificaram relação positiva entre o sombreamento da vegetação e a porcentagem de sobrevivência da espécie e encontraram o maior índice de sobrevivência (94,2\%) no capoeirão e o menor (60,8\%) na capoeirinha, não havendo diferença estatística em relação à altura das plântulas.

Nesse aspecto, estudos têm apontado que o nível de sombreamento adequado para a espécie está entre 20\% e 50\% (LEÃO; CARDOSO, 1974; REIS et al., 1988; MARTINS; SOUZA, 2009), principalmente nos primeiros três anos. Esse ambiente pode ser encontrado em pequenas clareiras com área inferior a cerca de $100 \mathrm{~m}^{2}$, como as que foram selecionadas para este trabalho. Porém, também é possível encontrar ambiente com níveis adequados de luz para transplante das mudas visando ao enriquecimento em florestas em estágios mais iniciais de sucessão (capoeiras). Em florestas em estágio sucessional mais avançado em áreas de Reserva Legal, onde o manejo florestal é permitido, o plantio de mudas de E. edulis em clareiras ou em faixas com raleamento do dossel e corte de cipós pode ser alternativa para a produção de palmito visando enriquecimento. O corte de cipós tende a favorecer a regeneração das espécies secundárias tardias (como E. edulis) e clímax do que os demais grupos ecológicos, em áreas em bom estado de conservação (SOUZA et al., 2002). Tal fato pode indicar a necessidade dessa intervenção nas condições deste estudo.

Bovi et al. (1992) verificaram comportamentos diferenciados da emergência e sobrevivência de $E$. edulis introduzido em mata com limpeza de sub-bosque (50\% de insolação) e em mata fechada, sem limpeza do sub-bosque (25\% de insolação).Também, observaram

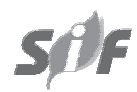

Revista Árvore, Viçosa-MG, v.35, n.6, p.1219-1226, 2011 
maior emergência na área menos sombreada e maior sobrevivência na área mais sombreada, assim como maiores médias de altura das plantas.

Schaefer (1999) observou diferença significativa a $5 \%$ entre as mudas transplantadas para os tratamentos de Radiação Alta e Radiação Moderada (média de 254,91 e $24,26 \mathrm{Mmol} / \mathrm{m}^{2}$.s, respectivamente), apresentando a menor e maior porcentagem de sobrevivência (50\% e 95\%, respectivamente) após 19 meses. O tratamento de Radiação Baixa (média de 3,71 Mmol $/ \mathrm{m}^{2}$.s) não diferiu dos demais tratamentos, apresentando $80 \%$ de sobrevivência. O elevado índice pluviométrico e a frequente neblina naquela região podem ter contribuído para a elevada sobrevivência das plântulas transplantadas. Da mesma forma que neste estudo, não houve diferença significativa entre os tratamentos em relação ao crescimento em altura, o qual foi muito lento ao longo do período.

A comparação entre os resultados desses trabalhos torna-se limitada em razão das diferentes metodologias aplicadas e das condições edafoclimáticas particulares de cada área de estudo, embora abordem a mesma espécie num mesmo bioma. No entanto, tais estudos indicam que o ponto ótimo de luminosidade da espécie é prejudicado em níveis muito altos (a pleno sol) ou muito baixos de luminosidade.

Em florestas mais secas com ocorrência da espécie, como as Florestas Estacionais Semideciduais, nota-se grande queda de folhas durante a estação seca, provocando aumento significativo na espessura da serapilheira. A velocidade de decomposição desse material também diminui, em razão das menores temperaturas e umidades do ar e do solo, favorecendo seu acúmulo. Em alguns casos, isso pode provocar o abafamento e até a cobertura das plântulas, sobretudo as menores (altura inferior a $20 \mathrm{~cm}$ ), dificultando a fotossíntese e a respiração, o que pode ter contribuído para elevar a mortalidade e reduzir o ritmo de crescimento das plântulas transplantadas. No caso de folhas maiores e mais pesadas, como as do gênero Cecropia, sua queda pode, inclusive, causar a morte das plântulas por dano mecânico.

No estudo de Amaral et al. (2008), conduzido na mesma reserva, observou-se a predominância de espécies secundárias tardias tanto em pequenas clareiras (área inferior a $100 \mathrm{~m}^{2}$, abertura do dossel variando de 2,31\% a 22,29\%) quanto no sub-bosque ao redor dessas áreas. Euterpe edulis, pertencente a esse grupo de espécies, ocorreu nos dois nichos de regeneração avaliados.

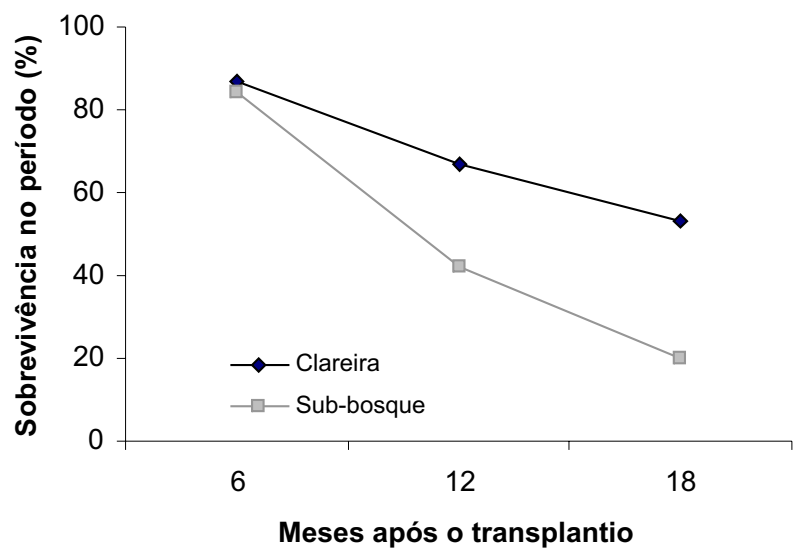

Figura 2-Média da porcentagem de sobrevivência por tratamento (clareira x sub-bosque), ao longo de 18 meses após o transplantio.

Figure 2-Average of survival percentage per treatment (gap $x$ understory), over 18 months after transplant.

Em Florestas Semidecíduas, essas espécies mostram grande adaptação à variação do regime de luz ao longo do ano, provocado, sobretudo, pela queda sazonal de folhas de boa parte das árvores que compõem o dossel (MARTINS, 2004).

Observou-se também que a mortalidade das plântulas transplantadas foi mais acelerada entre o sexto e o décimo segundo mês (Figura 2), o que corresponde ao período de abril a outubro de 2008, refletindo a forte influência da disponibilidade hídrica no solo com o estabelecimento das plântulas, já que nesse período do ano ocorrem os menores índices pluviométricos mensais na região (marcada estacionalidade climática). A queda expressiva de folhas no período também pode ter potencializado esse efeito, sobretudo no sub-bosque, onde o grau de ocupação do espaço é maior e a tendência de acúmulo da serapilheira também.

\section{AGRADECIMENTOS}

Ao CNPq, pela bolsa de Iniciação Científica de Ribeiro,T.M., de pós-graduação de Lana,V.M. e de Produtividade em Pesquisa de Martins, S.V.

\section{REFERÊNCIAS}

AMARAL, C. H. et al. Caracterização do dossel e do estrato de regeneração natural no sub-bosque e em clareiras de uma Floresta Estacional Semidecidual no município de Viçosa-MG. Revista Árvore, v.32, n.4, p.749-757, 2008. 
BARUQUI, F. M.; RESENDE, M.;

FIGUEIREDO, M. S. Causas da degradação e possibilidades de recuperação das pastagens em Minas Gerais (Zona da Mata e Rio Doce). Informe Agropecuário, v.11, n.128, p.27-37, 1985.

BOVI, M. L. A. Híbridos de palmiteiro. In: ENCONTRO SOBRE PRODUÇÃO DE PALMITO,1993, Piracicaba. Anais... Piracicaba: CALQ, 1993. p.39-48, 1993.

BOVI, M. L. A. et al. Eficiência de métodos de semeadura de palmiteiro: efeitos na emergência, sobrevivência e vigor das plantas. Revista do Instituto Florestal, v.4 (único), p.573-582, 1992.

BRAZ, D. M.; CARVALHO-OKANO, R. M.; KAMEYAMA, C. Acanthaceae da Reserva Florestal Mata do Paraíso, Viçosa, Minas Gerais. Revista brasileira de Botânica, v.25, n.4, p.495-504, 2002.

BRITO, E. R., MARTINS, S. V. Restauração de florestas inundáveis - Ipucas - na planície do Araguaia, Tocantins, por meio do resgate de plântulas de espécies arbóreas nativas. Ação Ambiental, n.36, p.20-21, 2007.

CORRÊA, G. F. Modelo de evolução e mineralogia da fração argila de solos do planalto de Viçosa, MG. 1984. 187f.. Dissertação (Mestrado em Solos) - Universidade Federal de Viçosa, Viçosa, MG, 1984.

FANTINI, A. C.; RIBEIRO, R. J.; GURIES, R. P. Produção de palmito (Euterpe edulis Martius Arecaceae) na floresta ombrófila densa: potencial, problemas e possíveis soluções. Sellowia, n.49/ 52, p.256-80, 2000.

GOLFARI, L. Zoneamento ecológico do Estado de Minas Gerais. Belo Horizonte: Centro de Pesquisa Florestal da Região do Cerrado, 1975. 65p.

LEÃO, M.; CARDOSO, M. Instruções para a cultura do palmiteiro (Euterpe edulis Mart.). Campinas: Instituto Agronomico de Campinas, 1974. 18p. (Boletim Técnico do IAC)
LEAL FILHO, N. Caracterização do banco de sementes de três estádios de uma sucessão vegetal na Zona da Mata de Minas Gerais. 1992. 116f. Dissertação (Mestrado em Ciência Florestal) - Universidade Federal de Viçosa, Viçosa, MG, 1992.

LIN, S. S. Efeito do tamanho e maturidade sobre a viabilidade, germinação e vigor do fruto de palmiteiro. Revista Brasileira de Sementes, v.8, n.1, p.57-66, 1988.

MARTINS, S. V. Colonization of gaps produced by death of bamboo clumps in a semideciduos mesophytic forest in southeaster Brazil. Plant Ecology, v.172, n.1, p.121-131, 2004.

MARTINS, S. V.; SOUZA, M. N. Cultivo do Palmiteiro-juçara. Viçosa, MG: Aprenda Fácil, 2009. 107 p.

MARTINS, S. V.; DE LIMA, D. G. Cultura de Palmeiras I: Palmiteiro (Euterpe edulis Mart.). Viçosa, MG: Universidade Federal de Viçosa, 1999. 28p. (Série Cadernos Didáticos, 54)

MORTARA, M. O.; VALERIANO, D. M. Modelagem da distribuição potencial do palmiteiro (Euterpe edulis Martius) a partir de variáveis topográficas. In: SBSR,10., 2001, Foz do Iguaçu. Anais... Foz do Iguaçu:: INPE, 2001. p.459-471, (Sessão Técnica Oral)

PAREJA, E. K. Utilização de banco de plântulas das espécies Emmotum nitens, Ocotea spixiana e Mouriri eliptica, na recuperação de áreas degradadas do Cerrado, TO. Gurupi: Universidade de Tocantins, 1998.

REIS, M. S. et al. Manejo sustentável do palmiteiro. In: Euterpe edulis Martius (Palmiteiro): biologia, conservação e manejo. Itajaí: Herbário Barbosa Rodrigues, 2000.

REIS, M. S.; GUERRA, M. P. Euterpe edulis Martius (Palmito). Florianópolis: Projeto "Inventário dos Recursos florestais da Mata Atlântica”. 1999.

Revista Árvore, Viçosa-MG, v.35, n.6, p.1219-1226, 2011 
REIS, M. S. et al. Desenvolvimento do palmiteiro: I. Caracterização até os 18 meses sob diferentes níveis de sombreamento. In: PALMITO:

ENCONTRO NACIONAL DOS PESQUISADORES, 1., 1987, Curitiba. Anais...Curitiba: EmbrapaCNPF, 1988. p.1-143. (Documento 19).

REZENDE, S. B. Estudo de cronotoposeqüência em Viçosa, Minas Gerais. 1971. 71f. Dissertação (Mestrado em Solos) Universidade Federal de Viçosa, Viçosa, MG, 1971.

SCHAEFER, S. M. Estudo da regeneração e transplante de mudas de palmiteiro (Euterpe edulis Martius) em diferentes condições de perturbação e luminosidade da Floresta Atlântica (SP). Dissertação (Mestrado em Recursos Florestais) - Escola Superior de Agricultura Luiz de Queiroz, Piracicaba, 1999. 75f.

SILVA JÚNIOR, W. M. et al. Regeneração natural de espécies arbustivo-arbóreas em dois trechos de uma Floresta Estacional Semidecidual, Viçosa, MG. Scientia Florestalis, n.66, p.169-179, 2004.
SOUZA, A. L. et al. Dinâmica da composição florística de uma Floresta Ombrófila Densa Secundária, após corte de cipós, Reserva Natural da Companhia Vale do Rio Doce S.A., estado do Espírito Santo, Brasil. Revista Árvore, v.26, n.5, p.549-558, 2002.

VELOSO, H. P.; RANGEL FILHO, A. L. R.; LIMA, J. C. A. Classificação da vegetação brasileira, adaptada a um sistema universal. Rio de Janeiro: Instituto Brasileiro de Geografia e Estatística, 1991.

VIANI, R. A. G.; NAVE, A. G.; RODRIGUES, R. R. Transference of seedlings and aloctone young individuals as ecological restoration methodology. In: RODRIGUES, R. R.; MARTINS, S. V.;

GANDOLFI, S. (Eds.) High diversity forest restoration in degraded areas: methods and projects in Brazil. New York: Nova Science Publishers, 2006.

YAMAZOE, G. S. et al. Enriquecimento de vegetação secundária com Euterpe edulis Mart. Revista do Instituto Florestal, v.2, n.1, p.55-67, 1990. 